\title{
Mega-aortic surgery: The whole enchilada or divide and conquer
}

\author{
Joseph S. Coselli, MD
}

\footnotetext{
From the Division of Cardiothoracic Surgery, Michael E. DeBakey Department of Surgery, Baylor College of Medicine; Adult Cardiac Surgery, Texas Heart Institute; and Cardiovascular Service, Baylor St Luke's Medical Center, Houston, Tex.

Disclosures: Author has nothing to disclose with regard to commercial support.

Received for publication Oct 4, 2017; accepted for publication Oct 7, 2017; available ahead of print Nov 7, 2017

Address for reprints: Joseph S. Coselli, MD, One Baylor Plaza, BCM 390, Houston, TX 77030 (E-mail: jcoselli@ bcm.edu).

J Thorac Cardiovasc Surg 2018;155:505-6

$0022-5223 / \$ 36.00$

Copyright (c) 2017 by The American Association for Thoracic Surgery

https://doi.org/10.1016/j.jtcvs.2017.10.021
}

For extensive, complex aortic surgery, the ideal treatment to provide both the best possible short-term results and longterm durability remains mired in controversy. Individualization is paramount. The aortic surgeon should be armed with an extensive armamentarium of choices to manage such complex patients. Historically, patients with mega-aortic pathology of the ascending aorta, aortic arch, and thoracoabdominal aorta have been managed with 2 or more operations - the first relying on a median sternotomy and the second using a left-sided thoracotomy or thoracoabdominal approach; rarely, a single procedure is used to repair extensive aortic pathology.

Matsueda and colleagues ${ }^{1}$ describe single-stage aortic replacement from the ascending aorta into the aortic arch and through the thoracoabdominal aorta, which was used in 14 patients who underwent operation over a 10-year period. Their early results were excellent with only a single mortality in a patient who had a postoperative myocardial infarction and stroke. In addition, their long-term results were good: Survival at 5 years was $97 \%$, and freedom from subsequent aortic events at 5 years was $91 \%$, with an average follow-up of approximately 6 years. Their technique uses a left thoracoabdominal approach to completely replace the aortic arch and to perform an extensive thoracoabdominal aortic aneurysm repair. Ten patients had received a previous ascending aortic graft, which was used to secure the proximal aspect of the replacement graft during mega-aortic repair.

It is important to recognize that this was a carefully curated group of patients from a highly experienced surgical center (during the same time period as this series, 818 total arch replacements and 85 extent II Crawford thoracoabdominal aneurysm repairs were performed at the authors' institution). The 14 patients tended to be young, with a mean age of 53.6 years, and in good health, as indicated by a mean left ventricular ejection fraction of $61.7 \%$ and a mean forced expiratory volume in 1 second of $84.8 \%$. The patients primarily had chronic aortic dissection

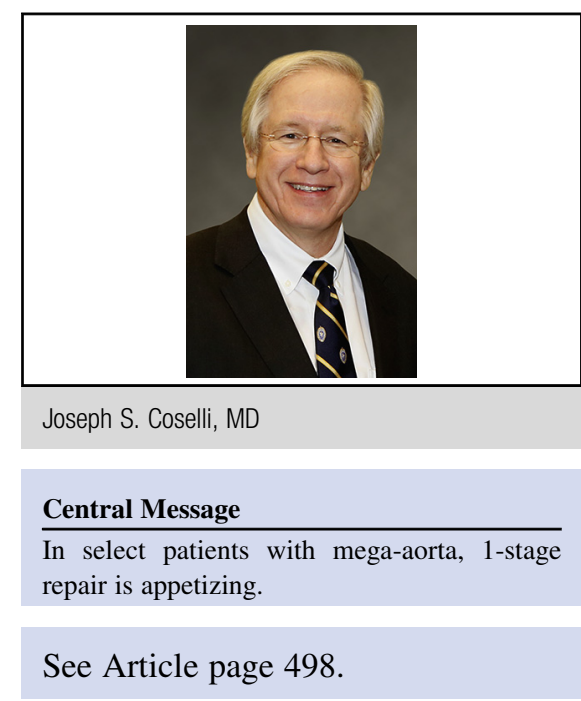

(13 patients), although acute dissection was present in 1 patient. Finally, the authors specifically state that patients with significant frailty should avoid such an extensive procedure.

Matsueda and colleagues ${ }^{1}$ rightfully point out that multiple staged operations necessitated by the classic elephant trunk approach carries the morbidity and mortality risk of 2 procedures, as well as an interim risk of death. Further, after the first procedure, many patients, especially those with many comorbidities, never end up undergoing the second procedure. In this report on extensive 1-stage repair, the increased risk of pulmonary complications secondary to bronchial hemorrhage in patients undergoing cardiopulmonary bypass and full heparinization through the left chest are noted by the authors. However, they rightfully point out that pulmonary complications occur at a generally acceptable rate and would present with a single- or dualstage open approach. Although hybrid and endovascular approaches to address extensive, mega-aortic pathology have had only sporadic experience and have a long way to go before they are the standard of care for combined aortic arch and Crawford extent II thoracoabdominal aortic aneurysms, a recent report by Gkremoutis and colleagues ${ }^{2}$ successfully demonstrated a hybrid mega-aortic approach in a series of 15 patients who underwent a 3-staged hybrid repair with only 1 death. Other experience with emerging technologies for such extensive repair is largely anecdotal.

In our experience, we too have been highly selective with regard to arch and thoracoabdominal aneurysm replacement at a single setting. We have previously shown that the classic, 2-stage elephant trunk operation can be performed 
with acceptable mortality and morbidity risks. ${ }^{3}$ Further, we have also shown that thoracoabdominal aortic aneurysm repair can be carried out in a dedicated program, also with good results. ${ }^{4}$ I commend Matsueda and colleagues ${ }^{1}$ for their openness in stressing the importance of patient selectivity for these single-stage procedures. The authors, assessing the operative risk of this series, point out that their patients undergoing this single-stage procedure were generally young (most in their mid-50s) and no one was aged more than 75 years.

Patients with severe chronic obstructive pulmonary disease, considering the additional pulmonary risk that operation carries, are at increased jeopardy. Certainly, patients who have severe frailty should also consider a staged aortic procedure or even nonoperative medical management. Patients at advanced age are a cohort for whom consideration for nonoperative management may be the best course of action. In our own work regarding open thoracoabdominal aortic aneurysm repair in octogenarians, we found octogenarians are at a prohibitive operative risk, especially those undergoing Crawford extent II thoracoabdominal aortic aneurysm repair. ${ }^{5}$

If we have learned anything from Matsueda and colleagues, ${ }^{1}$ individualization and selectivity armed with capabilities for a variety of approaches will continue to rule the day. For carefully selected patients, repair done in one big bite may be the most appetizing.

\section{References}

1. Matsueda T, Ikeno I, Yokawa K, Koda Y, Henmi S, Inoue T, et al. One-stage replacement of the aorta from arch to thoracoabdominal region. J Thorac Cardiovasc Surg. 2018;155:498-504.

2. Gkremoutis A, Zierer A, Schmitz-Rixen T, El-Sayed Ahmad A, Kaiser E, Keese M, et al. Staged treatment of mega aortic syndrome using the frozen elephant trunk and hybrid thoracoabdominal repair. J Thorac Cardiovasc Surg. 2017;154:1842-9.

3. LeMaire SA, Carter SA, Coselli JS. The elephant trunk technique for staged repair of complex aneurysms of the entire thoracic aorta. Ann Thorac Surg. 2006;81:1561-9.

4. Coselli JS, LeMaire SA, Preventza O, de la Cruz KI, Cooley DA, Price MD, et al. Outcomes of 3309 thoracoabdominal aortic aneurysm repairs. J Thorac Cardiovasc Surg. 2016;151:1323-37.

5. Aftab M, Songdechakraiwut T, Green SY, Zarda S, Price MD, Nalty CC, et al. Contemporary outcomes of open thoracoabdominal aortic aneurysm repair in octogenarians. J Thorac Cardiovasc Surg. 2015;149:S134-41. 